\title{
ACUTE CONJUNCTIVITIS CAUSED BY A GRAM-NEGATIVE DIPLOCOCCUS RESEMBLING THE GONOCOCCUS
}

By A. F. HAYDEN, B.A. (Cantab.) and A. F. HAYDEN, M.B., B.S. (Lond.), F.R.C.S., Captain I.M.S. (ret.).

[From the Inoculation Department, St. Mary's Hospital.]

ThE following notes seem to lend interest to at least one of those many relatively nameless members of the Neisseria which are found in the upper respiratory tract.

In November, I937, a hospital patient coughed into the right eye of one of us (an apprentice to medicine) a quantity of sputum which required forcible lavage for its removal. No sign appeared until the morning of the fifth day after the accident, when the recipient was aroused from sleep by the rapid development of an acute conjunctivitis in the same eye. There was intense vascular engorgement with local œdema; no ulcer or other cause could be seen; the intense pain necessitated morphia, and there was profuse lachrymation, but no pus formation, although this occurred later. A loopful of tears on a blood-agar plate gave rise within twentyfour hours incubation to a copious and pure growth of a typical Neisserian coccus, of which the similarities to and the differences from the gonococcus will be shown in due course.

The hospital patient had now been found to have florid secondary syphilis. In view of the frequency of the co-existence in the same patient of syphilis and gonorrhœa, and also the recording from time to time of the presence of gonococcus in the pharynx of cases of gonorrhœa, the culture was tested serologically. The result, within the claims of the particular technique used (Price's), would have classified the organism as a gonococcus, a finding which, not being quite in accord with preconceived notions, we decided to investigate further. Meanwhile we shall refer to the microbe as " Coccus X."

The conjunctivitis subsided in a few days; much more v.D. 


\section{BRITISH JOURNAL OF VENEREAL DISEASES}

rapidly than is usual with a gonorrhœal infection. On the tenth day a culture of the conjunctival sac grew a few colonies of Coccus X, as did also a culture of postnasal secretion. Six weeks later, the conjunctiva being sterile, a post-nasal swab yielded an almost pure mass growth. At no time was the left eye infected.

On the tenth day the blood serum of the victim with conjunctivitis was tested for the first time and found to give a strongly positive gonococcal complement fixation reaction (almost complete fixation of 5 M.H.D. of complement), a finding which persisted whenever the blood was tested during four months after the onset.

The original patient, presumed to be the donor of the infection, was found by cultures of post-nasal secretion and sputum to be harbouring a coccus, identical both morphologically and by the serological tests which follow with Coccus $X$. His blood had given a doubtful positive gonococcal fixation reaction, but a thorough examination of this case in the V.D. clinic by Dr. G. L. M. McElligott failed to reveal any evidence of gonorrhœa. Similarly, there was no evidence of gonorrhœea in the victim.

\section{EXPERIMENT I}

This was performed at the outset of the infection as a tentative investigation of the infecting organism (Coccus $\mathrm{X}$ ), the behaviour of which as an antigen was compared with that of a stock gonococcus antigen made by Price's method, in a complement fixation test with a pooled normal human serum and a pooled serum known to give a strongly positive reaction in the G.C.F. routine test. The antigen of Coccus $\mathrm{X}$ was a simple emulsion made to correspond in microbic titre with the stock antigen. The results are shown in Table $I$.

The table shows that Coccus $\mathrm{X}$ reacted more strongly with anti-gonococcal serum than did the standard antigen, in spite of a significant difference between the two antigens in respect of anti-complementary power which will be discussed later. As has been stated, the coccus isolated from the throat of the venereal patient gave an identical response.

A comparison of this organism on the basis of cultural characteristics with gonococcus, and with a Group 2 meningococcus used in serological tests described below, 


\section{ACUTE CONJUNCTIVITIS}

TABLE I.-Results of Experiment I.

\begin{tabular}{|c|c|c|c|c|c|c|c|c|}
\hline \multirow{2}{*}{ Antigen Source } & \multirow{2}{*}{ Serum Source } & \multirow{2}{*}{$\left|\begin{array}{c}\text { Controls } \\
\text { without } \\
\text { Antigen }\end{array}\right|$} & \multicolumn{6}{|c|}{ Dilutions of Antigen; $\mathrm{I}$ in } \\
\hline & & & 30 & 60 & 120 & 240 & 480 & 960 \\
\hline \multirow{2}{*}{$\begin{array}{l}\text { Stock } \\
\text { gonococcal }\end{array}$} & $\begin{array}{l}\text { Anti- } \\
\text { gonococcal }\end{array}$ & $\mathrm{H}$ & $\mathrm{O}$ & $\mathrm{O}$ & HP & $\mathbf{H}$ & $\mathrm{H}$ & $\mathrm{H}$ \\
\hline & Normal . & $\mathrm{H}$ & $\mathrm{H}$ & $\mathrm{H}$ & $\mathrm{H}$ & H & $\mathrm{H}$ & $\mathrm{H}$ \\
\hline \multirow{2}{*}{ Coccus X. } & $\begin{array}{l}\text { Anti- } \\
\text { gonococcal }\end{array}$ & $\mathrm{H}$ & $\mathrm{O}$ & $\mathrm{O}$ & $\mathrm{O}$ & HP & HP & $\mathrm{H}$ \\
\hline & Normal & $\mathrm{H}$ & $\mathrm{H}$ & $\mathrm{H}$ & $\mathrm{H}$ & $\mathrm{H}$ & $\mathrm{H}$ & $\mathrm{H}$ \\
\hline
\end{tabular}

Antigen quantities, O.I c.c. of each dilution in all but the control tubes; O.I c.c. saline in the latter.

Serum inactivated, $\mathbf{O} \cdot \mathbf{I}$ c.c. pooled positive or negative, as the case may be.

Complement, guinea-pig, 2 M.H.D. (= 0.1 c.c. of a $1 / 30$ dilution) in the controls.

3 M.H.D. ( $=0 \cdot 1$ c.c. of a $1 / 20$ dilution) in the antigen tubes.

Incubation thirty minutes at $37.8^{\circ} \mathrm{C}$., followed by the addition of hæmolytic indicator.

Cells, o.I c.c. of 3 per cent. sheep cells with 5 M.H.D. amboceptor.

Incubation, thirty minutes at $37 \cdot 8^{\circ} \mathrm{C}$.

Readings after a further hour on the bench at bench temperature.

Explanation of abbreviations : $H=$ complete lysis.

$$
\begin{aligned}
\mathrm{HP} & =\text { partial lysis } \\
\mathrm{O} & =\text { no lysis. }
\end{aligned}
$$

showed a greater likeness to the meningococcus. The similarities are :-

(a) All three are Neisseria.

(b) If cultured side by side by a method of " punctate" implantation on a hydrocele agar plate, all three give rise to apparently single colonies which at the end of seventy-two hours may be indistinguishable one from another in size and habit of growth.

(c) The growth of each on any suitable medium when scraped into a heap has the same café-au-lait colour.

(d) Growth of all three is inhibited by Penicillin; this has been shown by Fleming (I932) to inhibit only pathogenic Neisseria.

(e) All three rapidly die out in cultures unless special precautions are taken.

$(f)$ None grows at room temperature.

The dissimilarities are :-

(I) Fresh blood in a blood-agar plate seems to retard the gonococcus and to stimulate the other two. After punctate planting, the meningococcus and Coccus $\mathrm{X}$ colonies rapidly outstrip those of the 
gonococcus, which remain as relatively insignificant dots. At the same time the gonococcus shows the characteristic spreading margin of the other two when examined with the hand lens.

(2) The strain of gonococcus here used did not grow on plain nutrient agar; the other two grew readily.

(3) The gonococcus ferments glucose and not maltose ; the others ferment both. As will be discussed later, the strain of gonococcus was strongly anti-complementary; the other two did not have this effect.

A search for similar organisms in the throats of other subjects showed them to be very prevalent, at least at that winter season. Of three patients with untreated gonorrhœa, all showed such colonies, two so profusely as to be almost in pure culture. One of these gave a pure culture of gonococcus in the urethral pus and an almost pure culture of Coccus $\mathrm{X}$ in his throat. Of thirty blood plates sown with post-nasal secretion in the asthma clinic, 20 per cent. showed such colonies. Later, a similar search in a few " catarrhal " patients gave 50 per cent. positives.

The likeness to meningococcus of the first two strains of Coccus X led us to send them to the Laboratory of the Ministry of Health where Dr. V. D. Allison very kindly submitted them to agglutination tests with a Group 2 meningococcus serum. The result was a weak positive reaction, which, as is well known, may also be given by gonococci.

\section{EXPERIMENT 2}

In Experiment 2 were compared a number of Neisseria on the same principle as in Experiment I. In this case all the antigens were simple emulsions made to correspond with one another on an opacity basis. They were prepared from twenty-four-hour growths on fully infected 3.5 inch petri plates. The growth was scraped off carefully with the smooth short edge of a microscope slide, emulsified in saline and formalinised. The medium was one used here for the growth of gonococcus, which is the least luxuriant of these Neisseria. It is trypsinised meat agar (Douglas) to which, when melted, is added 5 per cent. horse blood, after which the whole is heated to coagulate the blood; then, before solidification on 


\section{ACUTE CONJUNCTIVITIS}

cooling, ro per cent. hydrocele fluid is added and the medium poured.

The organisms compared in Experiment 2 as to their behaviour as antigens with a pooled serum giving a strongly positive gonococcal fixation reaction were as follows :-

(I) A recently isolated $M$. catarrhalis.

(2) A Group I meningococcus kindly given us by Dr. W. M. Scott.

(3) A Group 2 meningococcus from the same source.

(4) A gonococcus isolated two months previously and frequently subcultured, from a case of cervicitis.

(5) A gonococcus from the urethra of the patient referred to as giving at the same time a copious growth of a Coccus $\mathrm{X}$ in his post-nasal space.

(6) The Coccus $X$ mentioned under (5).

(7) The Coccus $X$ responsible for the conjunctivitis.

(8) A Neisseria found as a contamination of the first subculture of a gonococcus from a cervix, which at first resembled Coccus $\mathrm{X}$, but later developed a yellow pigmentation.

(9) A morphological analogue of Coccus $\mathrm{X}$ obtained in pure culture from the pharynx of another patient with gonorrhœal urethritis.

(Io) Another morphological analogue of Coccus X from an asthmatic.

The results are shown in Table 2 . The symbols used are as in the previous table.

TABLE 2.-Results of Experiment 2.

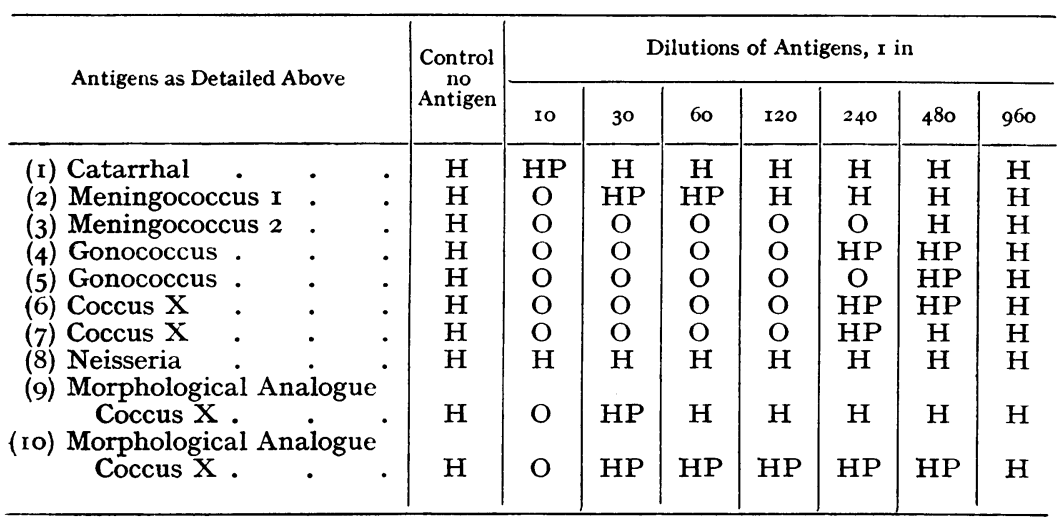




\section{BRITISH JOURNAL OF VENEREAL DISEASES}

The test shows a close relationship between the two gonococci, the meningococcus 2, and the strains of Coccus X; all five are in marked contrast with meningococcus $I$. The two control Neisseria, (I) and (8), give no response. No. (9) corresponds to the meningococcus $I$. No. (Io) gives an anomalous reaction; considering the frequency of these cocci it may well have been a mixed culture of two groups. Nos. (5) and (6) are of interest as coming from the same patient; some four months afterwards, though apparently cured of his gonorrhœea, he still carried a profusion of Coccus $\mathrm{X}$ in his pharynx. Among the few analogues of Coccus $\mathrm{X}$ isolated and tested in this way, the majority have corresponded with Coccus X.

It might appear from Experiment 2 that Coccus $\mathrm{X}$ or the meningococcus Group 2 might serve the purpose of an antigen in a routine G.C.F. test. In two short series of comparisons put up on this assumption the general agreement was striking, but there is a difference in anticomplementary power between the two classes of microbes which modifies certain results, and which will now be dealt with. Such an anti-complementary addition to fixation may be an advantage in increasing the sensitivity of a gonococcal antigen in the diagnosis of a gonorrhœal serum, but would be an embarrassment if present in the comparative tests of rabbit sera immunised to the three microbes which are described later.

The Anti-complementary Factor of a Gonococcal EMULSION

The diagram on page II of Price's monograph on gonococcal complement fixation suggests that his antigen fixes between 2 and 2.5 M.H.D. of complement in the test, a serious debit against the three M.H.D. used. In the few observations made by one of us on different samples of antigen prepared by Price's method, one showed a fixation of more than 4 M.H.D., while others have shown one of less than I.5 M.H.D., so that this factor would seem to vary widely. Also such antigens appear to be more anti-complementary than are simple emulsions of the same strain, and this may account for the fact that more positives are found by the use of his antigen than by the use of a simple emulsion. Such an 


\section{ACUTE CONJUNCTIVITIS}

artefactual gain may more than compensate the possibility that Price's method of preparation of antigen may result in a deterioration of antigenic titre ; a possibility suggested by a scrutiny of Experiments I and 2, and which has become a certainty in other tests not recorded here.*

Clearly, no test which neglects this variable can be considered to be standardised satisfactorily.

We found that a gonococcus emulsion to which glycerin had been added as a preservative had lost most of this anti-complementary action as soon as the rapid transparency resulting from the addition had reached a maximum. Thus of two concentrated preparations, identical except that in one of them two-thirds of the suspended medium was glycerin and in the other it was all saline, the $I$ in 30 dilution of the glycerin preparation fixed only a fraction of I M.H.D., while the corresponding dilution of the saline emulsion fixed between 2 and 3 M.H.D. ; so that by glycerination the gonococcus antigen was brought more into line with the other two Neisseria, neither of which was anti-complementary. Such glycerin preparations were used for all the microbes in the next experiment.

\section{Experiment 3, with Immunised Rabbit Sera}

Three rabbits previously found to give no agglutination reaction with any of the Neisseria used were immunised respectively against :

(I) A single strain of a typical gonococcus.

(2) The meningococcus Group 2 used in Experiment 2.

(3) Coccus X.

The same strains will, of course, be used for the subsequent tests.

The test consisted of two series of cross-fixations with the resulting sera. In the first series a constant quantum

\footnotetext{
* As regards any possible variations in antigenic titre, the first nineteen strains titrated by us as simple emulsions inclined us to agree with Price that there is no variation. The twentieth strain, however, differed from the others in an experiment like Experiment 2. Instead of resembling (3), (4), (5) and (6) in this test, it gave a reaction more closely resembling those of (2) and (9). Used as an antigen it was much less sensitive in a comparison of several batches of tests with the majority of positive sera, but an occasional gonorrhœal serum reacted more strongly with this twentieth strain than with the usual antigen. Circumstances have prevented us from any further pursuit of this observation with its suggestion of a grouping of strains of gonococcus possibly similar to the grouping of the meningococci.
} 


\section{BRITISH JOURNAL OF VENEREAL DISEASES}

of antigen was tested against varying dilutions of antiserum; in the second the quantum of anti-serum was constant and that of the antigen varied, as in Experiments I and 2. The unit volumes of materials and periods of incubation were also the same. The results were as shown in Table 3.

TABLE 3.-Results of Experiment 3.

SERIES I

\begin{tabular}{|c|c|c|c|c|c|c|c|c|}
\hline \multirow{2}{*}{ Antigens Diluted $\mathrm{r} / 50$} & \multirow{2}{*}{ Antisera } & \multicolumn{7}{|c|}{ Dilutions of Antisera, $\mathrm{I}$ in } \\
\hline & & 60 & 120 & 240 & 480 & 960 & 1,920 & 3,840 \\
\hline Gonococcus & $\begin{array}{l}\text { Gonococcus } \\
\text { Meningococcus } 2 . \\
\text { Coccus X }\end{array}$ & $\begin{array}{l}\mathrm{O} \\
\mathrm{O} \\
\mathrm{O}\end{array}$ & $\begin{array}{l}\mathrm{O} \\
\mathrm{O} \\
\mathrm{O}\end{array}$ & $\begin{array}{l}\mathrm{O} \\
\mathrm{O} \\
\mathrm{O}\end{array}$ & $\begin{array}{c}\mathrm{O} \\
\mathrm{HP}\end{array}$ & $\begin{array}{c}\text { HP } \\
\text { HP } \\
\mathbf{H}\end{array}$ & $\begin{array}{c}\text { HP } \\
\mathbf{H} \\
\mathbf{H}\end{array}$ & $\begin{array}{l}\mathbf{H} \\
\mathbf{H} \\
\mathbf{H}\end{array}$ \\
\hline $\begin{array}{l}\text { Meningococcus, } \\
\text { Group } 2 .\end{array}$ & $\begin{array}{l}\text { Gonococcus } \\
\text { Meningococcus } 2 . \\
\text { Coccus X }\end{array}$ & $\begin{array}{l}\mathrm{O} \\
\mathrm{O} \\
\mathrm{O}\end{array}$ & $\begin{array}{l}\mathrm{O} \\
\mathrm{O} \\
\mathrm{O}\end{array}$ & $\begin{array}{l}\mathrm{HP} \\
\mathrm{O} \\
\mathrm{HP}\end{array}$ & $\underset{\mathbf{H P}}{\mathbf{H}}$ & $\begin{array}{c}\mathbf{H} \\
\mathbf{H P}\end{array}$ & $\begin{array}{l}\mathbf{H} \\
\mathbf{H} \\
\mathbf{H}\end{array}$ & $\mathrm{H}$ \\
\hline Coccus $\mathrm{X}$. & $\begin{array}{l}\text { Gonococcus } \\
\text { Meningococcus } 2 . \\
\text { Coccus X }\end{array}$ & $\begin{array}{l}\mathrm{O} \\
\mathrm{O} \\
\mathrm{O}\end{array}$ & $\begin{array}{r}{ }^{\infty} \mathrm{O} \\
\mathrm{O} \\
\mathrm{O}\end{array}$ & $\begin{array}{c}\text { HP } \\
\text { OP }\end{array}$ & $\begin{array}{c}\mathbf{H} \\
\mathbf{H P}\end{array}$ & $\begin{array}{l}\mathbf{H} \\
\mathbf{H} \\
\mathbf{H}\end{array}$ & $\begin{array}{l}\mathbf{H} \\
\mathbf{H} \\
\mathbf{H}\end{array}$ & \\
\hline
\end{tabular}

TABLE 3.-Continued.

SERIES 2

\begin{tabular}{|c|c|c|c|c|c|}
\hline \multirow{2}{*}{ Antisera Diluted $\mathrm{r} / 60$} & \multirow{2}{*}{ Antigens } & \multicolumn{4}{|c|}{ Dilutions of Antigens, $I$ in } \\
\hline & & 50 & 100 & 200 & 400 \\
\hline Gonococcus & $\begin{array}{l}\text { Gonococcus } \\
\text { Meningococcus } 2 . \\
\text { Coccus X }\end{array}$ & $\begin{array}{l}\mathrm{O} \\
\mathrm{O} \\
\mathrm{O}\end{array}$ & $\begin{array}{c}\mathrm{O} \\
\mathrm{HP} \\
\mathrm{O}\end{array}$ & $\begin{array}{l}\mathrm{O} \\
\mathrm{HP} \\
\mathrm{HP}\end{array}$ & $\begin{array}{l}\mathbf{H} \\
\mathbf{H} \\
\mathbf{H}\end{array}$ \\
\hline $\begin{array}{l}\text { Meningococcus, } \\
\text { Group } 2 .\end{array}$ & $\begin{array}{l}\text { Gonococcus } \\
\text { Meningococcus } 2 . \\
\text { Coccus } \mathrm{X} .\end{array}$ & $\begin{array}{l}\mathrm{O} \\
\mathrm{O} \\
\mathrm{O}\end{array}$ & $\begin{array}{l}\text { HP } \\
\mathrm{O} \\
\mathrm{O}\end{array}$ & $\begin{array}{l}\mathbf{H} \\
\mathrm{HP} \\
\mathbf{H P}\end{array}$ & $\begin{array}{l}\mathbf{H} \\
\mathbf{H} \\
\mathbf{H}\end{array}$ \\
\hline 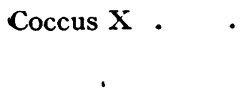 & $\begin{array}{l}\text { Gonococcus } \\
\text { Meningococcus } 2 . \\
\text { Coccus X }\end{array}$ & $\begin{array}{l}\mathrm{O} \\
\mathrm{O} \\
\mathrm{O}\end{array}$ & $\begin{array}{c}\text { HP } \\
\text { O } \\
\text { O }\end{array}$ & $\begin{array}{l}\mathbf{H} \\
\mathbf{H P} \\
\mathbf{H P}\end{array}$ & $\begin{array}{l}\mathbf{H} \\
\mathbf{H} \\
\mathbf{H}\end{array}$ \\
\hline
\end{tabular}

With regard to Series I, the stronger fixation shown by the gonococcus antigen with all the sera was probably due to this antigen's non-specific anti-complementary effect, this not having been entirely eliminated by glycerination. In Series 2 the anti-complementary effect of the gonococcus antigen is not disclosed, having been diluted out. In both series each antigen has to some 


\section{ACUTE CONJUNCTIVITIS}

degree picked out its own anti-serum and vice versâ. But we regard the differences as rather of degree than kind, and such as might occur between strains within the same antigenic group.

\section{Cross Agglutinations and Absorptions of AGGLUTININS}

Agglutinations, cross agglutinations, and absorption of agglutinins revealed evidence, as in the complement fixation tests, of pronounced antigenic reactions common to all three cocci ; but, again, inherent variations likely to stultify any strict conclusions as to real differences were observed; thus the meningococcus emulsion was more readily agglutinated by all the sera than were the other two emulsions.

Our absorption tests were inconclusive; perhaps for reasons stated by $\mathbf{M}$. H. Gordon (I9I8), when he wrote: "In its practical application to Gram-negative cocci the absorption tests upon which the final decision rests is work demanding a very high degree of dexterity that can only be acquired by continuous and persevering effort."

On the other hand, considering the views of $\mathrm{J}$. A. Arkwright (I93I) that "These two species"-(i.e., meningococcus and gonococcus) - " are often quite indistinguishable by agglutination and absorption technique," and that "certain strains of each appear to have identical antigens, that is, to belong to the same subgroup," we judged it expedient to subscribe to the latter (and later) of these two dicta and pursued this line of enquiry no further.

\section{SUMMARY}

A diplococcus, here referred to as Coccus $\mathrm{X}$, morphologically indistinguishable from gonococcus and meningococcus, has been found in the throats of a high proportion of hospital patients, and in one case has produced a violent conjunctivitis somewhat resembling a gonorrhœal ophthalmia, but differing from it in its shorter duration and the lateness of any suppuration. The coccus has been found culturally to resemble a meningococcus of Group 2 more than a gonococcus, but its antigenic properties in complement fixation tests with sera from 


\section{BRITISH JOURNAL OF VENEREAL DISEASES}

patients infected with gonorrhœe have been exactly the same as those of this meningococcus, and the reaction. of both of them in these tests has been indistinguishable from that of the gonococcus. In this respect it has differed from $M$. catarrhalis, a meningococcus Group $\mathrm{I}$, and certain other Neisseria. Also cross-fixation tests with sera of rabbits immunised respectively against gonococcus, the meningococcus Group 2, and Coccus X have shown such a close correspondence as to suggest that all of them belong to a common group.

The results suggest that the views of some workers to the effect that a gonococcal complement fixation test is practically specific and that cross-fixation is a negligible factor may require revision.

We are content to classify Coccus $\mathrm{X}$ as one of those Neisseria commonly found in the post-nasal space and frequently observed during the early work on cerebrospinal fever and as belonging to meningococcus Group 2. It is improbable that any epidemiological significance can be attached to the frequency of the finding of these microbes in the post-nasal space, as a similar frequency was noted during the early work referred to when spotted fever was epidemic.

It is unnecessary to emphasise its interest as the cause of an acute conjunctivitis derived from a patient suffering from a venereal disease.

We are indebted to the Inoculation Department, St. Mary's Hospital, for the facilities for carrying out this work.

\section{REFERENCES}

ARKwright, J. A. (I93I) : "Agglutination" in Medical Research Council's "A System of Bacteriology in Relation to Medicine," 6, pp. 4I9 to 420. H.M. Stationery Office.

Fleming, A. (I932): "On the Specific Antibacterial Properties of Pencillin and Potassium Tellurite," Jour. Path. \& Bact., 35, 83I.

GoRDon, M. H. (I9I8) : "Identification of the Meningococcus," Jour. Hyg., 17, 290.

PrICE, I. N. O. (I933): "The Complement Fixation Test for Gonorrhœa." London County Council. 